\title{
Adjustment and testing comparison of absolute gravimeters in November 2013
}

\author{
Alena Pešková* and Martin Štroner \\ Czech Technical University in Prague, Czech Republic \\ ${ }^{*}$ Corresponing author: alena.peskova@fsv.cvut.cz
}

\begin{abstract}
This paper is focused on a comparison measurement processing of absolute gravimeters in 2013. The comparison deals with a number of various types of absolute gravimeters and includes also an absolute gravimeter from Geodetic observatory Pecný. Comparative measurements are performed to detect systematic errors of gravimeters. A result of processing is most likely value of a gravity and a systematic error of individual devices. Measured values are input to a adjustment with condition a sum of systematic errors is zero. A part of this process is also verification following output: (i) value of a posteriori standard deviation, (ii) size of corrections and (iii) statistical significance of systematic errors. The results of adjustment are 15 gravity values on the reference places and 25 systematic errors of measuring instruments. Result shows that the presence of systematic errors in measurements is not statistically provable because the systematic errors are similarly sized as their standard deviation.
\end{abstract}

Keywords: absolute gravimeter; adjustment with condition; systematic error; gravity.

\section{Introduction}

Since 1981 international comparisons of absolute gravimeters are regularly hold, a goal is to detect systematic errors of these gravimeters [10]. For this purpose repeated measurements of absolute gravimeters on reference places in laboratory and also measurement by superconducting gravimeter in the same time are used. In a case of this study an analysis of a comparison measurement which took place in November 2013 in the underground laboratory for geodynamics in Walferdange, Luxembourg is applied. Twenty-five gravimeters participated in the comparison including a new prototype from China.

The goal of this study is to determine gravity value at the individual places of measurement and based on this to estimate a systematic error of individual devices and a standard deviation of it's measurement. An integral part of the calculation is an individual gravimeters accuracy verification. During the measurement event there was also used one absolute gravimeter FG5 from Geodetic observatory Pecný, the Czech Republic. An absolute gravimeters are used for periodic measurement on geodetic gravity points, in such a case and its change are determined. Measurement results are used for creating of a geoid model which is important for an elevation determination. By analyzing a gravity field of Earth it is possible to localize failure in homogenity of the earth's crust and it can be e.g. used for locating deposits of mineral resources.

\section{The current state of the problem}

The current accuracy determination of gravity value is approximately $1 * 10-7 \mathrm{Gal}(1 \mathrm{Gal}=$ $1 \mathrm{~cm} / \mathrm{s}^{2}$ in SI units) and it has been achieved thanks to a gradual improvement of measurement techniques. The only way how to estimate accuracy is a comparison of devices between each 
other on a single base. These International Comparisons of Absolute Gravimeters (ICAG) have been regularly organized since 1981. The first eight comparisons have taken place in Bureau International des Poids et Mesures in France and since 2003, the other comparisons have taken place in Walferdange in Luxembourg [17]. "Free-fall" method is a main method for gravity measurement since 2004 [12].

\section{Used instruments}

There were used seven types of absolute gravimeters for comparison, these instruments used three methods of determination of the gravity value. During the whole comparison measurement a gravity change was measured by superconducting gravimeter. Following paragraphs presents a brief description of gravimeters and a principle of a gravity determination.

\subsection{Free-fall gravimeter}

This type of gravimeter measures a gravity value by tracking of the free fall trajectory (especially the time) in the vacuum. Interference rings are produce by a falling optical prism in a drop chamber and this optical output is converted to electrical signal. The position is obtained by counting and measuring of rings' occurrence time, the possition is a function of time which is then used for the gravity value determination [13]. The most common gravimeters are represented by FG5, there were 13 devices of this type. One result of measurement by gravimeter FG5 is calculated using at least 600 recorded pairs of position and time while 100-200 falls during one hour can be done [14]. This detail is a good estimate of comparison measurement duration. More technical specifications of this gravimeter are available on the manufacturer's website http://www.microglacoste.com/fg5.php.

The gravimeter FG5X is the second most used absolute gravimeter in the experiment. There were 6 devices of this gravimeter type in the comparison measurement. This gravimeter is an improved version of type FG5, where the improvement consists of an improved drop chamber for free-fall and a better electronic control [12].

An advantage of gravimeter A10 is a device optimalization for its using outside laboratory conditions, for example greater compactness and lower weight. The gravimeter consist of a drop chamber and an interferometer. The interferometer contains a laser which is capable to emitt laser beams of two different wavelengths. Gravity measurement uses the same observation principle of mass fall by laser's interferometer as previous devices. The resulting gravity is determined as a mean of two laser beams measurement [11]. Details are available on the manufacturer's website http://www.microglacoste.com/a10.php. In laboratory conditions is performed 100 fall during one hour of measurement for determining gravity [12].

The chinese gravimeters NIM-3A and T-2 belong between two new prototypes. Gravimeter NIM-3A is constructed for long time continuous observation, difference lies in the rotating drop chamber along the horizontal axis. Free fall of optical prism is caused by turning a drop chamber to the vertical position. Fall parameters are determined by the interferometer [8].

\subsection{Atomic gravimeter}

The gravimeter CAG-01 operates on an atom release basis; its acceleration is determined by the interferometry [2]. Free fall of atom is conducted in the space between two laser beams 


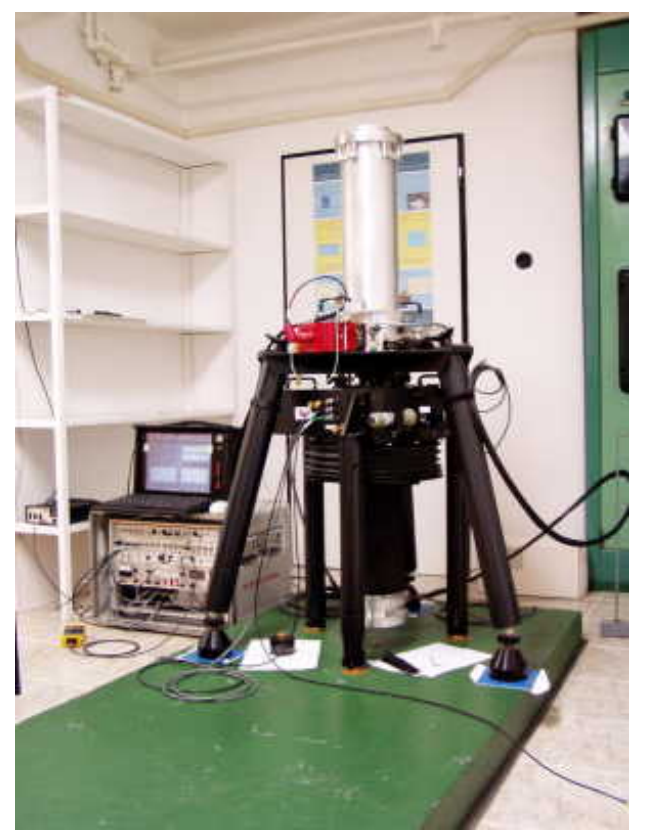

Figure 1: Absolute gravimeter FG5 n.215, Geodetic observatory Pecný.

which determines its trajectory position. The gravimeter consists of two parts - a gravimeter core is formed by a seismometer and a vacuum chamber placed in a magnetic cylinder; the second part is composed of an optical and an electronic bench. As gravimeter precision is influenced by ambient conditions, e.g. ground vibrations, this gravimeter belongs to group of laboratory gravimeters [5].

\subsection{Rise-and-fall gravimeter}

The italian gravimeter IMGC02 is the only gravimeter working on the principle "rise-and-fall". Gravity is determined by measuring of the ascending and the descending symmetric vertical trajectory of the body. The measuring set consists of 200 starts approximately $[9,1]$. The device allows a speed about 120 starts during the hour. Gravimeter consists of five parts - a catapult in a vacuum chamber, an interferometer, a laser, a photodetector and a supporting frame [4].

Table 1: Gravimeter accuracy provided by operators.

\begin{tabular}{|c|c|}
\hline Absolute gravimeter & Uncertainty $[\mu \mathrm{Gal}]$ \\
\hline \hline FG5 & $1.8-2.6$ \\
\hline FG5X & $2.0-2.3$ \\
\hline A10-006 & 10.7 \\
\hline A10-020 & $5.2-5.5$ \\
\hline IMGC02 & 5.3 \\
\hline CAG-01 & $5.3-5.4$ \\
\hline NIM-3A & $4.9-5.2$ \\
\hline T-2 & 5.0 \\
\hline
\end{tabular}




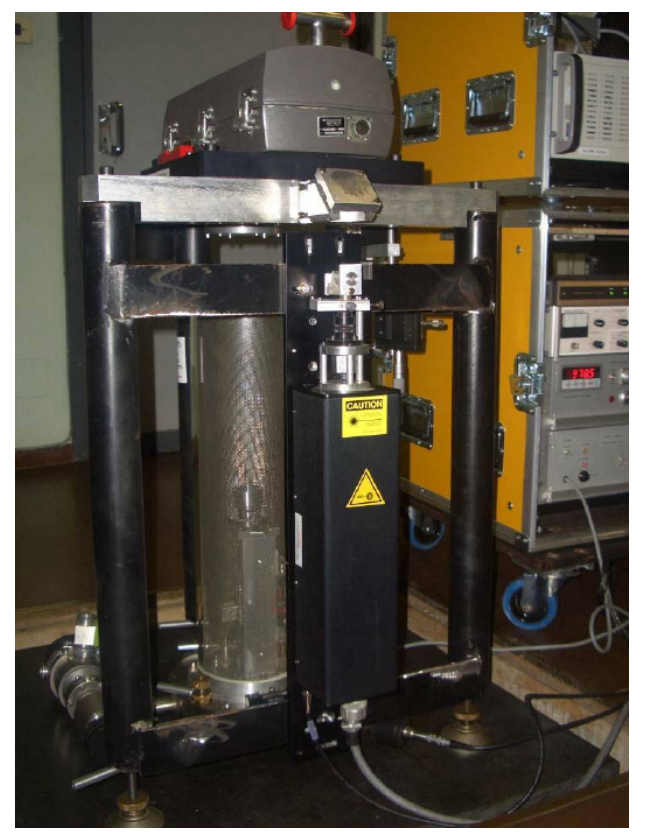

Figure 2: Absolute gravimeter IMGC-02.

\subsection{Superconducting gravimeter}

The superconducting gravimeter OSG-CT040 was used for monitoring gravity changes during the whole comparison measurement. The monitored mass is located in a magnetic field generated by superconducting magnets. A gravity change causes the monitored mass movement; this movement is monitored by the sensor and electromagnetically compensated. An accuracy of a gravity change determination is given to $0.1-0.4 \mu \mathrm{Gal}[16,15]$.

\subsection{Relative gravimeter}

Relative gravimeters are used only to determinate a gravity change between places. The gravity change is given by voltage value. This voltage is supplied on compensator plates while the distance between plates stays constant. The measurement was used to determine coefficients a, b being part of the calculation of vertical gravity gradient. This gradient is used for correction gravimeter measurement made in various heights to the reference height. The resolution of relative gravimeter is $1 \mu \mathrm{Gal}$ and the accuracy is $<5 \mu \mathrm{Gal}[3]$.

\section{Measurement procedure}

There were used 15 reference measurement places in underground laboratory (fig. 3). The schedule has been designed in order to all 25 gravimeters could have measured successively on 3 reference places. The gravimeter FG5 n.242 measured only once on one reference place because it had a serious malfunction without any repairing possibility. There were carried out 4-6 measurements by each gravimeter on one reference place. The measurement event was divided into two stages. The first stage taked place 5.-7. November 2013 and the second stage taked place 12.-14. November 2013. An exception is the gravimeter CAG-01 because it needed more space for measurement. This device measured in advance, 24.-28.October 2013. 
The second exception was the gravimeter FG5 n.223 which couldn't measure at November so that alternative date was set up in February 2014 for measurement by this device.

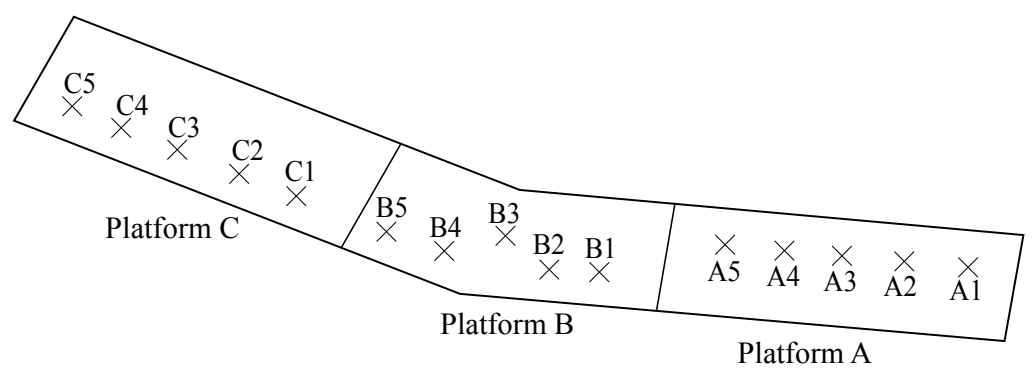

Figure 3: Sketch of the underground laboratory for geodynamics in Walferdange.

The superconducting gravimeter OSG-CT040 recorded the gravity changes during measurement by absolute gravimeters. These measurements was adjusted by the same corrections of the earth and atmospheric tides as measurement by absolute gravimeters. All of the measurements were moved to the same date due to settings of correction; the correction was set to zero on 9th november 2013. Operators provided acceleration averages of free fall at different height adjusted by corrections, standard deviations of averages and uncertainties. The uncertainties include all known device's contributions [6].

\section{Preparation for processing}

The operators rectified their data using following corrections:

1. the earth tides including the ocean tides and associated influences

2. the atmospheric tides and associated influences with input factor $-0.3 \mu \mathrm{Gal} / \mathrm{hPa}$ to difference between atmospheric pressure from standard measurement model and local atmospheric pressure

3. the impact of polar motion is estimated from position of the poles, International Earth Rotation and Reference Systems Service (IERS) provided the data on polar motion

4. vertical gravity gradient

5. the other known devices influences, e.g. influence of their self-attraction, laser beam diffraction correction, etc.

The operators provided the data which were not in the same ordinary height due to the data were transferred to reference height $1.3 \mathrm{~m}$. The reference heights are different for various types of devices. The vertical gravity gradient was used after transferring of data from operators to reference height. It was used polynomial (1).

$$
g(z)=a \cdot z^{2}+b \cdot z+c
$$

The coefficients $a, b$ were different for various reference places in laboratory and it were determined by a measurement. The coefficient $c$ was neglected. These coefficients were determined by the measurement in November 2013, one week after the comparison measurement event. 
The relative gravimeters CG5\#008 and CG5\#542 were used for this measurement, which taked place on all of the places in laboratory and also in three heights $0.26 \mathrm{~m}, 0.86 \mathrm{~m}$ and $1.27 \mathrm{~m}$. The polynomial allows transfer the value of gravity along the vertical axis to reference height.

Before the calculation by the Least squares method (LSM) it was checked deployment of the vertical gravity gradient (using repeated calculation) which was used due to transfer data to reference height $1.3 \mathrm{~m}$. To simplify a calculation the measured gravity value is reduced by the constant value $980960000.0 \mu \mathrm{Gal}$.

\section{Systematic errors determination of a measuring instruments}

Determination of gravity value on reference places in the laboratory is the result of processing measured data. Another result is an estimation of systematic errors of individual absolute gravimeters with theirs standard deviations. The used calculation method is the LSM.

\subsection{The least squares method adjustment of the measurement}

The measured gravity on various points of the same height and uncertainty of gravimeters from operators are inputs into the least squares adjustment with conditions. Observation equation has the form:

$$
g_{i k}=g_{k}+\delta_{i}+\epsilon_{i k}
$$

where $g_{i k}$ represents gravity value on place $k$ measured by the device $i, g_{k}$ is adjusted value on place $k, \delta_{i}$ represents a systematic error of a measuring instrument and $\epsilon_{i k}$ is a random error. The adjustment is performed according to [7] with contidion:

$$
\sum \delta_{i}=0 .
$$

The weight matrix is created by an inverse square of uncertainties gravimeters $1 / \sigma^{2}$. The adjusted values are gravity on places and systematic error of a measuring instruments.

The weight matrix $\mathbf{P}$ has a dimension $73 \times 73$, there are inverse squares of uncertainties for each gravimeter on a diagonal axis:

$$
\mathbf{P}=\left[\begin{array}{cccc}
\frac{1}{\sigma_{1}^{2}} & 0 & 0 & 0 \\
0 & \frac{1}{\sigma_{2}^{2}} & 0 & 0 \\
0 & 0 & \cdots & 0 \\
0 & 0 & 0 & \frac{1}{\sigma_{73}{ }^{2}}
\end{array}\right]
$$

The design matrix $\mathbf{A}_{\mathbf{1}}$ has a dimension 73 rows by a count of measurement and 40 columns by a count unknown - gravity on places (A1-C5) and systematic errors of measuring instruments $(\delta 1-\delta 25)$.

$$
\mathbf{A}_{1}=\left[\begin{array}{ccccccccccccc}
\frac{\partial x_{1}}{\partial A 1} & \frac{\partial x_{1}}{\partial A 2} & \ldots & \frac{\partial x_{1}}{\partial A 5} & \frac{\partial x_{1}}{\partial B 1} & \ldots & \frac{\partial x_{1}}{\partial B 5} & \frac{\partial x_{1}}{\partial C 1} & \ldots & \frac{\partial x_{1}}{\partial C 5} & \frac{\partial x_{1}}{\partial 1_{1}} & \ldots & \frac{\partial x_{1}}{\partial \delta 25} \\
\frac{\partial x_{2}}{\partial A 1} & \frac{\partial x_{2}}{\partial A 2} & \ldots & \frac{\partial x_{2}}{\partial A 5} & \frac{\partial x_{2}}{\partial B 1} & \ldots & \frac{\partial x_{2}}{\partial B 5} & \frac{\partial x_{2}}{\partial C 1} & \ldots & \frac{\partial x_{2}}{\partial C 5} & \frac{\partial x_{2}}{\partial \delta 1} & \ldots & \frac{\partial x_{2}}{\partial \delta 25} \\
\vdots & \vdots & \vdots & \vdots & \vdots & \vdots & \vdots & \vdots & \vdots & \vdots & \vdots & \vdots & \vdots \\
\frac{\partial x_{73}}{\partial A 1} & \frac{\partial x_{73}}{\partial A 2} & \ldots & \frac{\partial x_{73}}{\partial A 5} & \frac{\partial x_{73}}{\partial B 1} & \ldots & \frac{\partial x_{73}}{\partial B 5} & \frac{\partial x_{73}}{\partial C 1} & \ldots & \frac{\partial x_{73}}{\partial C 5} & \frac{\partial x_{73}}{\partial \delta 1} & \ldots & \frac{\partial x_{73}}{\partial \delta 25}
\end{array}\right]
$$


A vector $\mathbf{B}$ complemented the matrix $\mathbf{A} 1$ so that the condition - zero sum of systematic error was fulfilled. The matrix result of normal equations $\mathbf{A}$ has the form:

$$
\mathbf{A}=\left[\begin{array}{cc}
\mathbf{A}_{\mathbf{1}}^{T} \cdot \mathbf{P} \cdot \mathbf{A}_{\mathbf{1}} & \mathbf{B} \\
\mathbf{B}^{T} & \mathbf{0}
\end{array}\right]
$$

The vector $\mathbf{B}$ is a column vector with a dimension $40 \mathrm{x} 1$, where the first 15 rows are filled by 0 (reference places) and other 25 rows is filled by 1 (using gravimeters), thus guarantees the condition fulfillment mentioned above. A vector of measured values $\mathbf{l}_{\mathbf{0}}$ has a dimension $73 \mathrm{x} \mathbf{1}$ and it is also modified into a new shape $\mathbf{l}$ :

$$
\begin{gathered}
\mathbf{l}_{\mathbf{0}}=\left[\begin{array}{c}
l_{1} \\
l_{2} \\
\vdots \\
l_{73}
\end{array}\right], \\
\mathbf{l}=\left[\begin{array}{c}
\mathbf{A}_{\mathbf{1}}^{T} \cdot \mathbf{P} \cdot \mathbf{l}_{\mathbf{0}} \\
\mathbf{b}
\end{array}\right] .
\end{gathered}
$$

Based on the matrices and vectors described before it is possible to set a system of normal equations for adjustment using conditions for unknowns:

$$
\left(\begin{array}{cc}
\mathbf{A}_{\mathbf{1}}^{T} \cdot \mathbf{P} \cdot \mathbf{A}_{\mathbf{1}} & \mathbf{B} \\
\mathbf{B}^{T} & \mathbf{0}
\end{array}\right)\left(\begin{array}{c}
\mathbf{d x} \\
\mathbf{k}
\end{array}\right)+\left(\begin{array}{c}
\mathbf{A}_{\mathbf{1}}^{T} \cdot \mathbf{P} \cdot \mathbf{l}_{\mathbf{0}} \\
\mathbf{b}
\end{array}\right)=0 .
$$

The futher calculation procedure is the same as the classic adjustment [7]. The adjustments by LSM method provide 15 values of gravity on reference places and 25 systematic errors of a measuring instruments. The results are in following tables 2 and 3 :

\subsection{The result verification and testing}

The results of adjustment were checked and tested by these following ways according to [7]. The first assessed quantity was the value of a posteriori standard deviation, for this purpose two-sided test $\chi^{2}$ was used. The zero hypothesis:

$$
H_{0}: \sigma_{\text {apriori }}=\sigma_{\text {aposteriori }}
$$

The tested values are $\sigma_{\text {priori }}=1$ and $\sigma_{\text {posteriori }}=0.7998$. The zero hypothesis $H_{0}$ is not rejected based on the test for level of importance $5 \%$. It means the aposteriori standard deviation coincides with apriori standard deviation. This fact confirms that the accuracy of measurement corresponds to an assumption and the apriori standard deviation can be used for other needs.

The posteriori standard deviation value was also tested using permitted sample standard deviation for the probability $95 \%$ :

$$
S_{M}=\sigma \cdot\left(1+\sqrt{\frac{2}{n^{\prime}}}\right),
$$


Table 2: The gravity on reference places $[\mu \mathrm{Gal}]$ with the subtracted constant value $980960000.0 \mu \mathrm{Gal}$ and their standard deviations.

\begin{tabular}{|c|c|c|}
\hline Reference place & Gravity & Standard deviation \\
\hline \hline A1 & 4228.6 & 1.6 \\
\hline A2 & 4215.8 & 1.6 \\
\hline A3 & 4206.5 & 1.3 \\
\hline A4 & 4190.0 & 1.1 \\
\hline A5 & 4183.2 & 1.5 \\
\hline B1 & 4077.4 & 1.5 \\
\hline B2 & 4071.8 & 1.2 \\
\hline B3 & 4068.8 & 1.3 \\
\hline B4 & 4062.4 & 1.5 \\
\hline B5 & 4049.4 & 1.3 \\
\hline C1 & 3951.4 & 1.2 \\
\hline C2 & 3945.9 & 1.8 \\
\hline C3 & 3948.6 & 1.2 \\
\hline C4 & 3946.4 & 1.4 \\
\hline C5 & 3942.7 & 1.3 \\
\hline & \multicolumn{2}{|c|}{} \\
\hline
\end{tabular}

where $n^{\prime}=33$ is a number of redundant observations. The permitted selection deviation was not exceeded, $\sigma_{\text {apriori }}<\sigma_{M}$.

The second assessment quantities were the size of corrections evaluated by permitted correction:

$$
v_{M}=\sigma_{v} \cdot u_{p},
$$

where

$$
\sigma_{v}=\sigma_{0} \cdot\left(\mathbf{P}^{-1}-\mathbf{A} \cdot\left(\mathbf{A}^{T} \cdot \mathbf{P} \cdot \mathbf{A}\right)^{-1} \cdot \mathbf{A}^{T}\right)_{i i}
$$

$u_{p}=2$ the probability $95 \%$ and $u_{p}=2.5$ the probability $99 \%$. The permitted values were not exceeded for any selected value $u_{p}$.

The histogram of standardized corrections shows how the data set corresponds to the normal distribution. The left side of histogram does not fit to the normal distribution as well as the right side of histogram, it can be caused by a relatively small number of observations.

The last assessment quantity was the systematic errors of gravimeters. The testing was performed using permitted deviation:

$$
\delta_{M}=Q_{x} \cdot u_{p}
$$

for $u_{p}=2$ and $u_{p}=2.5$, where $Q_{x}$ are standard deviations of each calculated systematic error. The vector $Q_{x}$ has a dimension $25 \mathrm{x} 1$ and it's elements are the square rooted elements of the diagonal of covariance matrix $Q_{x x}$. Assuming, that apriori unit standard deviation was choosen to be 1 , the covariance matrix $Q_{x x}$ is determined by the following equation:

$$
Q_{x x}=\left(\begin{array}{cc}
\mathbf{A}_{\mathbf{1}}^{T} \cdot \mathbf{P} \cdot \mathbf{A}_{\mathbf{1}} & \mathbf{B} \\
\mathbf{B}^{T} & \mathbf{0}
\end{array}\right)^{\prime}
$$


Table 3: The systematic error of a measuring instruments and standard deviations, $[\mu \mathrm{Gal}]$.

\begin{tabular}{|c|c|c|}
\hline Gravimeter & Systematic error & $\begin{array}{c}\text { Standard deviation } \\
\text { of the systematic error }\end{array}$ \\
\hline \hline A10-006 & -2.7 & 6.0 \\
\hline A10-020 & -4.2 & 3.1 \\
\hline CAG-01 & 7.0 & 3.1 \\
\hline FG5-102 & -5.4 & 1.4 \\
\hline FG5-202 & 2.1 & 1.5 \\
\hline FG5-206 & -2.4 & 1.6 \\
\hline FG5-213 & -3.5 & 1.6 \\
\hline FG5-215 & 0.4 & 1.5 \\
\hline FG5-218 & 1.1 & 1.3 \\
\hline FG5-223 & 1.4 & 1.5 \\
\hline FG5-228 & -3.6 & 1.3 \\
\hline FG5-231 & -1.5 & 1.5 \\
\hline FG5-233 & 1.9 & 1.6 \\
\hline FG5-234 & 1.9 & 1.4 \\
\hline FG5-242 & 0.9 & 2.9 \\
\hline FG5-301 & -1.4 & 1.4 \\
\hline FG5X-104 & -0.8 & 1.4 \\
\hline FG5X-209 & -1.9 & 1.4 \\
\hline FG5X-216 & -0.7 & 1.4 \\
\hline FG5X-220 & 2.1 & 1.5 \\
\hline FG5X-221 & 1.4 & 1.6 \\
\hline FG5X-302 & 0.1 & 1.5 \\
\hline IMGC02 & -1.6 & 3.1 \\
\hline NIM-3A & 1.0 & 2.9 \\
\hline T-2 & 8.3 & 2.9 \\
\hline
\end{tabular}

For value $u_{p}=2$ the permitted deviation has been exceeded $5 \mathrm{x}$, for value $u_{p}=2.5$ the permitted deviation has been exceeded $3 \mathrm{x}$. This exceeding is statistically insignificant in most cases. The systematic errors are similarly sized as their standard deviation. Based on this fact the occurrence of systematic errors is not proven in the measurement.

\section{Conclusion}

The results of adjustment are 15 gravity values on the reference places and 25 systematic errors of measuring instruments. The systematic errors of devices correspond to the size of their standard deviations and therefore can not be considered to be proved. The problem solved struggles with the relatively small number of redundant observations. We determined 40 unknowns (15 gravity value on places and 25 sytematic errors of measuring instruments) from the 73 measured values; therefore there are only 33 redundant observations. The number of redundant observations can be increased by a larger number of repetitions on reference places, e.g. to increase repetition number from 3 to 4 ; this change would lead to an extension of time demands by a third. The measurement would take eight days instead of the original 


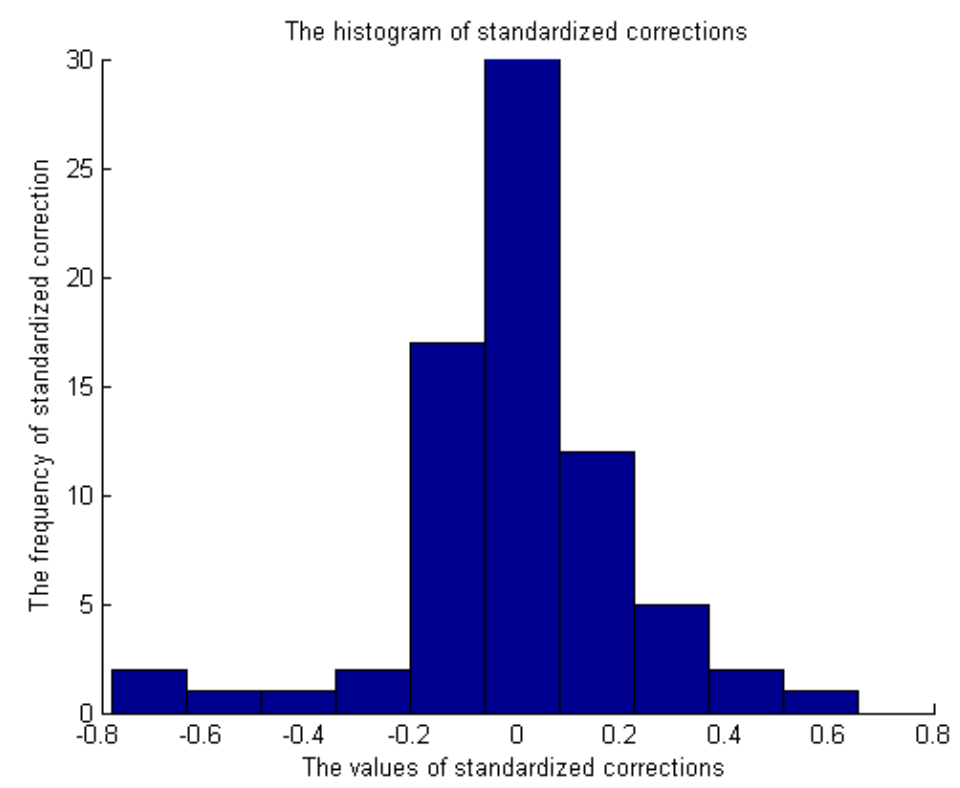

Figure 4: The histogram of standardized corrections.

6 days.

\section{Acknowledgements}

This work was supported by the Grant Agency of the Czech Technical University in Prague, grant No. SGS16/062/OHK1/1T/11 and it used data set from CCM.G-K2 Key Comparison and Pilot Study.

\section{References}

[1] G. Barbato et al. "Treatment of Experimental Data with Discordant Observations. Issues in Empirical Identification of Distribution". In: Measurement Science Review 12.4 (2012), pp. 133-140. DOI: 10.2478/v10048-012-0020-y.

[2] Yannick Bidel et al. "Compact cold atom gravimeter for field applications". In: Applied Physics Letters 102.14 (Apr. 2013), p. 144107. DOI: 10.1063/1.4801756.

[3] CG-5 Autograv Gravity Meter. Canada. URL: http://www. scintrexltd.com/gravity . html.

[4] G. DAgostino et al. "The new IMGC-02 transportable absolute gravimeter. measurement apparatus and applications in geophysics and volcanology". In: Annals of Geophysics 51.1 (2008), pp. 39-49. DOI: 10.4401/ag-3038.

[5] T. Farah et al. "Underground operation at best sensitivity of the mobile LNE-SYRTE cold atom gravimeter". In: Gyroscopy and Navigation vol. 5.issue 4 (2014), pp. 266-274. ISSN: 2075-1087. DOI: 10.1134/S2075108714040051. 
[6] Olivier Francis, Henri Baumann, et al. International Compari of Absolute Gravimeters: CCM.G-K2 Key Comparison. Tech. rep. University of Luxemburg, Federal Institute of Metrology METAS, Nov. 2014. URL: http://www . bipm.org/utils/common/pdf / final_reports/M/G-K2/CCM.G-K2.pdf.

[7] Miroslav Hampacher and Martin Štroner. Zpracování a analýza měření v inženýrské geodézii. Vyd. 1. Praha: České vysoké učení technické v Praze, 2011. ISBN: 978-80-0104900-6.

[8] H. Hanada et al. "New design of absolute gravimeter for continuous observations". In: Review of Scientific Instruments vol. 58.issue 4 (1987), pp. 669-673. ISSN: 0034-6748. DOI: $10.1063 / 1.1139237$.

[9] Il gravimetro IMGC-02. Italy. URL: http://www. nanospin.eu/res/grav/grav.html.

[10] Z Jiang et al. "The 8th International Comparison of Absolute Gravimeters 2009. the first Key Comparison (CCM.G-K1) in the field of absolute gravimetry". In: Metrologia 49.6 (Dec. 2012), pp. 666-684. ISSN: 0026-1394. DOI: 10.1088/0026-1394/49/6/666.

[11] Takahito Kazama et al. "Gravity measurements with a portable absolute gravimeter A10 in Syowa Station and Langhovde, East Antarctica". In: Polar Science vol. 7.3-4 (2013), pp. 260-277. ISSN: 18739652. DOI: 10.1016/j ·polar.2013.07.001.

[12] Micro-g LaCoste. a division of LRS. URL: http://www.microglacoste.com.

[13] T.M. Niebauer et al. "A new generation of absolute gravimeters". In: Metrologia 32.3 (1995), pp. 159-180.

[14] Vojtech Pálinkáš, Jakub Kostelecký, and Miloš Val'ko. "Charakteristiky přesnosti absolutního gravimetru FG5 č. 215”. In: Geodetický a kartografický obzor 58/100.5 (2012), pp. 97-102. ISSN: 0016-7096.

[15] Superconducting Gravity Sensors. 2015. URL: http://www.gwrinstruments.com/iosgsuperconducting-gravity-meters.html.

[16] Supravodivý gravimetr OSG-050. 2010. URL: http://oko.pecny.cz/pecny/supgrav . html.

[17] O de Viron, M Van Camp, and O Francis. "Revisiting absolute gravimeter intercomparisons". In: Metrologia 48.5 (Oct. 2011), pp. 290-298. ISSN: 0026-1394. DOI: 10.1088/ 0026-1394/48/5/008. 
